\title{
Analisis Sistem Premi Panen Kelapa Sawit Terhadap Kinerja dan Kepuasan Kerja Karyawan \\ (Studi Kasus: Unit Kebun Rambutan Perkebunan Nusantara III \\ Kecamatan Paya Bagas) \\ Analysis of Palm Oil Palm Harvest Salary System on Employee Performance and Employee Satisfactions \\ (Case Study: Rambutan Perkebunan Nusantara III Unit, Paya Bagas \\ District) \\ Fitra Aristia Fahmi Lubis, Siti Mardiana, \& Mitra Musika Lubis \\ Unversitas Medan Area, Indonesia
}

Diterima: April 2021 Direview: April 2021 Disetujui: April 2021

*Corresponding author: E-mail: fitraaristia@gmail.com

\begin{abstract}
Abstrak
Penelitian ini bertujuan untuk menganalisis sistem premi panen yang berlaku di lokasi penelitian dan untuk menganalisis pengaruh premi panen terhadap kinerja dan kepuasan kerja karyawan panen di lokasi penelitian. Penelitian ini dilaksanakan pada bulan September 2019 hingga Oktober 2019 di Unit Kebun Rambutan Perkebunan Nusantara III Kecamatan Paya Bagas, Kabupaten Serdang Bedagai. Lokasi penelitian ditentukan secara purposive dan teknik pengambilan sampel dalam penelitian ini adalah proportionate stratified random sampling dengan jumlah 38 sampel dari masing-masing afdeling. Dari hasil penelitian diperoleh kesimpulan bahwa system premi panen di PT. Perkebunan Nusantara III Kebun Rambutan adalah sistem basis tugas (BT) ditentukan berdasarkan kondisi topografi areal dan potensi produksi. Premi panen berpengaruh secara nyata terhadap kinerja (kuantitas kerja, kualitas kerja, kehadiran kerja) dan kepuasan kerja karyawan di PT. Perkebunan Nusantara III Unit Kebun Rambutan.
\end{abstract}

Kata Kunci: kinerja; kepuasan kerja; premi panen; karyawan panen kelapa sawit.

\begin{abstract}
This research was conducted on September - October 2019 at Rambutan Plantation unit PT. Perkebunan Nusantara III, PayaBagas Sub-District, Serdang Bedagai District. The location of this research determined purposively and the sampling technic in this research was proportionate stratified random sampling with a total of 38 samples from cast section (Afdeling). From the results of the research conduded that the harvest salary system in PT. Perkebunan Nusantara III Rambutan Plantation were a task bare system determined based on the area topography and potential production. Harvest salaries significantly affect the performance (quality of work, quantity of work, work attendance) in the PT. Perkebunan Nusantara III Rambutan Plantation Unit.
\end{abstract}

Keywords: performance; job satisfaction; harvest pay; oil palm harvest employees

How to Cite: Lubis, F.A.F. Mardiana, S. \& Lubis, M.M (2021). Analisis Sistem Premi Panen Kelapa Sawit Terhadap Kinerja dan Kepuasan Kerja Karyawan (Studi Kasus: Unit Kebun Rambutan Perkebunan Nusantara III Kecamatan Paya Bagas). Jurnal Agriuma. 3 (1): 40-49. 


\section{PENDAHULUAN}

Premi adalah pendapatan yang diperoleh pekerja apabila telah melampaui batas ketentuan yang ditetapkan pengusaha/perusahaan. Perusahaan perkebunan mengadakan sistem premi pada karyawan panen bertujuan untuk mendorong karyawan panen bekerja lebih giat, sehingga hasil peningkatan kualitas dan kuantitas akan mengakibatkan keuntungan bagi perusahaan (Ghani, 2003). Kinerja adalah tentang apa yang dikerjakan dan bagaimana cara mengerjakannya. Kinerja dibangun dan dipengaruhi oleh bagaimana karyawan tersebut melaksanakan tugas pekerjaannya dengan kemampuan, keterampilan dan motivasi yang dimilikinya. Keseimbangan dari beberapa elemen tersebut akan menghasilkan kinerja yang baik begitu juga sebaliknya (Wibowo, 2007). Kepuasan kerja merupakan suatu tanggapan emosional seseorang terhadap situasi dan kondisi kerja, tanggapan emosional bisa perusahaan puas (positif) atau tidak puas (negatif) (Sopiah, 2008).

Kebun Kelapa Sawit Unit Rambutan adalah salah satu bagian atau unit usaha PTPN III Medan - Sumatera Utara, yang terletak di kota Madya Tebing Tinggi yang memiliki dua komoditi tanaman perkebunan yaitu tanaman kelapa sawit dan tanaman karet. Selain itu unit rambutan juga mempunyai pabrik pengolahan hasil atau pasca panen untuk mengelolah hasil panen agar bisa dipasarkan dan menghasilkan keuntungan bagi perusahaan. Dalam meningkatkan produktivitas perusahaannya PT. Perkebunan Nusantara III Medan sangat memperhatikan sumber daya manusia atau karyawannya di dalam bekerja. Berbagai cara dan pendekatan dilakukan untuk terus memotivasi karyawan agar karyawan menghasilkan kinerja yang baik dan menguntungkan bagi perusahaan. Melakukan pengawasan dan evaluasi dan perbaikan juga dilakukan PT. Perkebunan Nusantara III untuk terus berkembang ke arah yang lebih baik. Salah satu bentuk evaluasi yang dilakukan PT. Perkebunan Nusantara III Medan adalah melakukan survey kepuasan dan motivasi karyawan yang dilakukan setiap tahunnya.

PT. Perkebunan Nusantara III Medan dalam mengukur kepuasan karyawannya di dalam bekerja mempunyai sebuah alat ukur berupa kuesioner, dimana kuesioner tersebut diberikan kepada karyawan untuk diisi pada setiap tahunnya. Kuesioner tersebut digunakan sebagai input informasi yang akurat mengenai kepuasan dan ketidakpuasan pada sistem manajemen PT. Perkebunan Nusantara III (Persero) Medan, sehingga dapat dilakukan perbaikan umtuk dapat memotivasi karyawan di tahun berikutnya. Dari hasil survey pada tahun 2015 terlihat bahwa kepuasan karyawan pada PTPN III sudah baik, hal ini dipengaruhi oleh faktor-faktor sebagai berikut: paket imbalan (gaji, tunjangan, lembur, bonus, BAS, THR); peluang untuk promosi dan pengembangan karir; dan peluang untuk mengikuti pelatihan yang dibutuhkan. Sedangkan faktor yang tidak memuaskan bagi karyawan PTPN III, antara lain: paket imbalan (premi dan gaji pensiun); fasilitas penunjang kesejahteraan (fasilitas rumah, kesehatan, sarana pendidikan, sarana olahraga, dan ibadah); rekrutmen yang kurang objektif dan transparan. Dari faktor-faktor tersebut terlihat bahwa premi merupakan salah satu faktor yang tidak memuaskan atau tidak memotivasi karyawan.

Berdasarkan latar belakang di atas peneliti tertarik untuk melihat bagaimana analisis sistem premi panen kelapa sawit terhadap kinerja dan kepuasan kerja karyawan di PT. Perkebunan Nusantara III (PTPN III) Persero. PTPN III adalah salah satu dari 14 Badan Usaha Milik Negara yang bergerak dalam bidang usaha perkebunan, yaitu mengelola tanaman karet dan kelapa sawit sebagai komoditi utamanya yang didukung dengan adanya pabrik pengolahan untuk masing masing komoditi tersebut (http:www.ptpn3.co.id/abus.htm/). Berdasarkan latar belakang di atas, maka dapat dirumuskan tujuan penelitian diantaranya menganalisis sistem premi panen yang berlaku, menganalisispengaruh premi panen terhadap kinerja karyawan panen serta 
menganalisis pengaruh premi panen terhadap kepuasan kerja karyawan panen di lokasi penelitian

\section{METODE PENELITIAN}

Penelitian ini akan dilaksanakan pada bulan Juni 2019, di Unit kebun kelapa sawit Kebun Rambutan PT Perkebunan Nusantara III (Persero), Kota Tebing Tinggi. Daerah penelitian ditentukan secara purposive. Menurut Sugiyono (2006), purposive merupakan metode/teknik yang diambil berdasarkan pertimbangan tertentu. Adapun pertimbangan-pertimbangan dalam penentuan daerah/lokasi penelitian ini, antara lain:

Perkebunan dengan komoditi kelapa sawit dipilih karena kelapa sawit merupakan komoditi yang paling banyak diusahakan di Sumatera Utara. PT. Perkebunan Nusantara dipilih karena merupakan perkebunan milik negara dan penghasil kelapa sawit yang cukup tunggi di Sumatera Utara setelah Perkebunan Rakyat. Perkebunan Rambutan PTPN III memiliki jumlah Afdeling cukup banyak dibandingkan kebun lainnya dengan dua komoditi yaitu, tanaman kelapa sawit dan tanaman karet.

Teknik pengambilan sampel yang digunakan dalam penelitian ini adalah Proportionate Stratified random sampling. Proportionate Stratified Random Sampling adalah teknik pengambilan sampel yang digunakan karena populasi mempunyai anggota atau unsur yang tidak homogen dan berstrata secara proporsional (Sugiyono, 2010).

Sampel yang digunakan dalam penelitian ini adalah karyawan panen PTPN III Unit Kebun Rambutan. Masa kerja karyawan panen dari delapan afdeling didapatkan dari data sekunder milik PTPN III Unit Kebun Rambutan. Jumlah sampel karyawan panen ditentukan peneliti berjumlah 38 sampel yang diambil berdasarkan strata atau kelas masa kerja karyawan panen. Peneliti mengambil sampel sebanyak 30\% dari masing-masing strata masa kerja karyawan panen untuk dijadikan sampel.

Pengumpulan data bersumber dari data primer dan data sekunder. Menurut Umar (2008) yang dimaksud data primer dan data sekunder adalah Data primer diperoleh dengan menyebarkan kuesioner dan melakukan wawancara secara langsung kepada karyawan Kebun Rambutan PT. Perkebunan Nusantara III (Persero) yang menjadi responden penelitian. Data sekunder diperoleh dari Dinas Perkebunan Sumatera Utara, PT. Perkebunan III, Unit Kebun Rambutan, Instansi-Instansi yang terkait, dan referensi yang berhubungan.

\section{Uji Validitas dan Uji Reliabilitas}

Validitas menunjukkan sejauh mana suatu alat pengukur itu mengukur apa yang ingin diukur. Suatu alat pengukur dikatakan valid apabila skala tersebut digunakan untuk mengukur apa yang seharusnya diukur (Situmorang dan Luthfi, 2012). Kriteria dalam menentukan validitas suatu kuesioner adalah:

Jika $r$ hitung $>r$ tabel maka pertanyaan tersebut valid.

Jika $r$ hitung $<$ r tabel maka pertanyaan tersebut tidak valid.

Reliabilitas adalah indeks yang menunjukkan sejauh mana suatu alat pengukur dapat dipercaya atau dapat diandalkan (Situmorang dan Luthfi, 2012). Reliabilitas dinyatakan jika nilai Cronbach Alpha $>0,60$ atau nilai Cronbach Alpha 0,80. Uji validitas dan reliabilitas kuesioner dalam penelitian ini dilakukan pada 38 orang karyawan PT. Perkebunan Nusantara III Unit Kebun Rambutan dengan menggunakan program SPSS.

\section{Analisis Regresi Linear Sederhana}


Analisis statistik dengan regresi linear sederhana adalah hubungan linear antara variabel bebas (Independent) dan variabel terikat (dependent). Analisis ini untuk mengetahui arah hubungan antara variabel bebas penerapan Sistem Premi Panen dengan variabel terikat Kinerja dan Kepuasan Kerja Karyawan apakah positif atau negatif.

Persamaan Regresi Linear Sederhana sebagai berikut:

$\mathrm{Y}_{1}=\mathrm{a}+\mathrm{bx}$

$\mathrm{Y}_{2}=\mathrm{a}+\mathrm{bx}$

Keterangan :

$\mathrm{Y}_{1}=$ Variabel terikat (Kinerja Karyawan panen)

$\mathrm{Y}_{2}=$ Variabel terikat (Kepuasan Kerja Karyawan Panen)

$\mathrm{X}_{1}=$ Variabel bebas (Sistem Premi Panen)

$\mathrm{A}=$ Konstanta (nilai $\mathrm{Y}$ apabila $\mathrm{X}=0$ )

$\mathrm{B}=$ Koefisien Regresi (nilai peningkatan dan penurunan)

\section{HASIL DAN PEMBAHASAN}

\section{Pengujian Hipotesis Penelitian}

Sistem premi panen dapat dilaksanakan oleh semua perkebunan kelapa sawit. Namun, oleh karena kondisi lapangan dan aspek-aspek sosial ekonomi yang berbeda antar kebun maka standar premi juga harus disesuaikan dengan perbedaan perbedaan tersebut. Perbedaan tersebut tercakup tarif berdasarkan basis tugas, tarif lebih borong, dan tarif sanksi/denda Basis Tugas (BT) ditentukan berdasarkan kondisi topografi areal dan potensi produksi (RKAP setahun) sesuai tabel 1 berikut :

Tabel 1. Penentuan Basis Tugas

\begin{tabular}{lcccc}
\hline \multirow{2}{*}{ TOPOGRAFI } & \multicolumn{4}{c}{ POTENSI (Ton/Ha) } \\
\cline { 2 - 5 } & $<12$ & $12-16$ & $17-21$ & $<21$ \\
\hline Rata $(100 \%)$ & 500 & 750 & 850 & 900 \\
\hline Berbukit & 400 & 600 & 700 & 750 \\
\hline Berbukit Tanpa Teras Kontur & 350 & 550 & 600 & 650 \\
\hline Rawa & 350 & 500 & 550 & 600 \\
\hline
\end{tabular}

\begin{tabular}{lcc} 
BT (Potensi 17-21 ton/Ha topografi rata) HK Efektif Setahun & Target BT setahun \\
\hline 850 & 292 & 248.200
\end{tabular}

Maka perhitungan Basis Tugas sebagai berikut:

$$
\begin{aligned}
& \text { Basis Tugas SM }-\mathrm{I}=\frac{248.200 \times 41,49 \%}{138}=746 \mathrm{~kg} \\
& \text { Basis Tugas SM - II }=\frac{248.200 \times 58,51 \%}{154}=943 \mathrm{~kg}
\end{aligned}
$$


Analisis yang digunakan pada penelitian ini adalah analisis regresi linier sederhana untuk mengetahuihubungan dan pengaruh variabel premi panen $(\mathrm{X})$ terhadap variabel kinerja karyawan (Y1) dan kepuasan karyawan (Y2) Unit Kebun PT. Perkebunan Nusantara III (Persero) Medan Kebun Rambutan. Adapun hasil regresi linier sederhana sebagai berikut:

\section{Variabel Kinerja Karyawan $\left(\mathrm{Y}_{1}\right)$ atau Pengaruh Sistem Premi Panen Terhadap Kinerja Karyawan}

Adapun hasil regresi linier sederhana variabel Premi panen (X) terhadap variabel Kinerja Karyawan $\left(\mathrm{Y}_{1}\right)$ adalah sebagai berikut :

Tabel 2. Hasil Uji Regresi Liner Sederhana Premi Panen terhadap Kinerja Karyawan

\begin{tabular}{|c|c|c|c|c|c|c|}
\hline \multicolumn{7}{|c|}{ Coefficients $^{\mathrm{a}}$} \\
\hline & & Unstandard & efficients & $\begin{array}{c}\text { Standardized } \\
\text { Coefficients }\end{array}$ & & \\
\hline \multicolumn{2}{|l|}{ Model } & $\mathrm{B}$ & Std. Error & Beta & $\mathrm{T}$ & Sig. \\
\hline \multirow[t]{2}{*}{1} & (Constant) & 21.337 & 6.011 & & 3.550 & .001 \\
\hline & PREMI PANEN & .501 & .102 & .634 & 4.915 & .000 \\
\hline
\end{tabular}

Berdasarkan hasil uji regresi linier sederhana tersebut, maka dapat diketahui persamaannya sebagai berikut :

Keterangan :

$\mathrm{Y}_{1}=$ Variabel terikat (Kinerja Karyawan)

$\mathrm{X}=$ Variabel Bebas (Premi Panen)

$\mathrm{A}=$ Konstanta (Nilai $\mathrm{Y}$ apabila $\mathrm{X}=0$ )

$\mathrm{B}=$ Koefisien Regresi (nilai peningkatan atau penurunan)

Berdasarkan persamaan tersebut maka dapat diketahui sebagai berikut:

Nilai konstanta (Y) sebesar 21,337 artinya jika variabel premi panen (X) nilainya 0 (nol), maka variabel kinerja karyawan $\left(\mathrm{y}_{1}\right)$ akan berada pada angka 21,337.

Koefisiens regresi X (Premi Panen) dari perhitungan linier sederhana didapat nilai koefisien (b) $=0,501$. Hal ini berarti setiap ada kenaikan premi panen $(X)$ maka kinerja karyawan (Y) juga meningkat.

\section{Uji Serempak (Uji F)}

Tabel 3. Hasil Uji Simultan (Uji F) Penelitian

\begin{tabular}{|c|c|c|c|c|c|c|}
\hline ANOVA & & & & & & \\
\hline Model & & Sum of Squares & Df & Mean Square & $\mathrm{F}$ & Sig. \\
\hline 1 & Regression & 92.790 & 1 & 92.790 & 24.160 & $.000^{\mathrm{a}}$ \\
\hline & Residual & 138.262 & 36 & 3.841 & & \\
\hline & Total & 231.053 & 37 & & & \\
\hline a. Predic & ctors: (Constant & Premi Panen & & & & \\
\hline b. Depen & ident Variable: & erja & & & & \\
\hline
\end{tabular}


Berdasarkan dari hasil penelitian yang diperoleh, dapat dilihat pada tabel diatas diketahui bahwa F-hitung sebesar 24,160 sedangkan nilai F-tabel untuk pembilang (df1) adalah K-l = 2-1 = 1, dan penyebut (df2) adalah $\mathrm{n}-\mathrm{k}=38-2=36$ dengan taraf signifikan sebesar $5 \%$ adalah 4,11. Maka diketahui bahwa nilai f-hitung variabel premi panen (X) yaitu 24,160 lebih besar dibandingkan nilai f-tabel yaitu 4,11 maka $\mathrm{H} 0$ ditolak $\mathrm{H} 1$ diterima. Begitu juga jika dilihat dari nilai signifikansi variabel premi panen (X) 0,000 < 0,05 maka H0 ditolak dan H1 diterima, jadi dapat dikatakan bahwa terdapat pengaruh antara variabel premi panen $(\mathrm{X})$ terhadap kinerja karyawan $\left(\mathrm{Y}_{1}\right)$.

\section{Uji Parsial (Uji t)}

Hubungan variabel independen terhadap variabel dependen dihitung dengan menggunakan uji statistik t (uji t). Apabila nilai t hitung > nilai t tabel, maka H0 ditolak, sebaliknya apabila nilai t hitung < nilai t tabel, maka H0 diterima. Untuk lebih jelas dapat dilihat pada tabel 4 berikut ini: Tabl4. Hasil Uji Parsial (Uji T) Penelitian

Coefficients $^{\mathrm{a}}$

\begin{tabular}{|c|c|c|c|c|c|c|}
\hline \multirow[b]{2}{*}{ Model } & & \multicolumn{2}{|c|}{ Unstandardized Coefficients } & \multirow{2}{*}{$\begin{array}{c}\text { Standardize } \\
\mathrm{d} \\
\text { Coefficients }\end{array}$} & \multirow[b]{2}{*}{$\mathrm{T}$} & \multirow[b]{2}{*}{ Sig. } \\
\hline & & $\mathrm{B}$ & Std. Error & & & \\
\hline \multirow[t]{2}{*}{1} & (Constant) & 21.337 & 6.011 & & 3.550 & .001 \\
\hline & PREMI PANEN & .501 & .102 & .634 & 4.915 & .000 \\
\hline
\end{tabular}

a. Dependent Variable: Kinerja Karyawan

Variabel Premi panen $(\mathrm{X})$ berpengaruh secara signifikan terhadap variabel Kinerja karyawan $\left(\mathrm{Y}_{1}\right)$. Diketahui bahwa nilai t-hitung untuk variabel premi panen $(\mathrm{X})$ adalah 4,915 sedangkan t-tabel dalam penelitian ini untuk derajat kebebasan $\mathrm{df}=\mathrm{n}-\mathrm{k}=38-2=36$ dengan nilai signifikansi 5\% adalah 1,68. Hal ini ditunjukkan pada hasil tabel coefficients di peroleh t-hitung untuk variabel premi panen (X) sebesar 4.915 lebih besar dari t-tabel yaitu 1,68, jika t-hitung lebih besar dari pada t-tabel maka $\mathrm{H} 0$ ditolak $\mathrm{H} 1$ diterima. Begitu juga jika dilihat dari nilai signifikansi variabel premi panen $(\mathrm{X})$ 0,000 $<0,05$ maka $\mathrm{H} 0$ ditolak dan $\mathrm{H} 1$ diterima, artinya variabel premi panen $(\mathrm{X})$ berpengaruh terhadap kinerja karyawan $\left(\mathrm{Y}_{1}\right)$.

Berdasarkan dari hasil tabel di atas, menunjukkan bahwa variabel premi panen (X) berpengaruh signifikan terhadap kinerja karyawan $\left(\mathrm{Y}_{1}\right)$. Dari hasil penelitian tersebut diketahui juga bahwa nilai koefisen refresi dari variabel premi panen (X) adalah sebesar 0,501 artinya, setiap kenaikan premi panen (X) sebesar Rp. 1000 maka akan meningkatkan kinerja karyawan $\left(\mathrm{Y}_{1}\right)$ sebesar $0,501 \%$. Dari hasil analisis regresi variabel premi panen $(\mathrm{X})$ terhadap variabel kinerja karyawan $\left(\mathrm{Y}_{1}\right)$ maka diperoleh persamaan:

$\mathrm{Y}_{1}=21,337+0,501 \mathrm{X}$

\section{Koefisien Determinasi $\left(\mathrm{R}^{2}\right)$}

Koefisien determinasi yang memiliki fungsi untuk menjelaskan sejauh mana kemampuan variabel independen (Premi Panen) terhadap variabel dependen (kinerja karyawan). Untuk lebih jelas dapat dilihat pada tabel 5. Berikut ini: 
Model Summary

\begin{tabular}{lllll}
\hline & & & \\
Model & $\mathrm{R}$ & R Square & Adjusted R Square & $\begin{array}{l}\text { Std. Error of the } \\
\text { Estimate }\end{array}$ \\
\hline 1 & $.634^{\mathrm{a}}$ & .402 & .385 & 1.960 \\
\hline a. Predictors: (Constant), Premi panen & \\
\hline
\end{tabular}

Berdasarkan dari hasil penelitian tersebut, dapat diketahui bahwa: angka R sebesar 0,634 hal ini menunjukkan bahwa korelasi hubungan antara variabel premi panen (X) dengan Kinerja Karyawan $\left(\mathrm{Y}_{1}\right)$. Sedangkan angka $\mathrm{R}$ square atau Koefisien Determinasi ( $\left.\mathrm{R}^{2}\right)$ adalah sebesar 0,402 (berasal dari 0,634 x 0,634). Hal ini menunjukkan bahwa 40,2\% variasi dari tingkat premi panen (X) bisa dijelaskan oleh variasi dari satu variabel independent. Seangkan sisanya $(100 \%-40,2 \%$ = 59,8\% mungkin dipengaruhi oleh variabel lainnya yang tidak dijelaskan pada penelitian ini.

Variabel Kepuasan Karyawan $\left(\mathrm{Y}_{2}\right)$ atau Pengaruh Sistem Premi Panen Terhadap Kepuasan Karyawan Panen

Adapun hasil regresi linier sederhana variabel Premi panen $(\mathrm{X})$ terhadap variabel Kepuasan Karyawan $\left(\mathrm{Y}_{2}\right)$ adalah sebagai berikut:

Tabel 6. Hasil Uji Regresi Liner Sederhana Premi Panen terhadap Kepuasan Karyawan

Coefficients $^{\mathrm{a}}$

\begin{tabular}{|c|c|c|c|c|c|c|}
\hline \multirow[b]{2}{*}{ Model } & & \multicolumn{2}{|c|}{ Unstandardized Coefficients } & \multirow{2}{*}{$\begin{array}{l}\text { Standardized } \\
\text { Coefficients } \\
\text { Beta }\end{array}$} & \multirow[b]{2}{*}{$\mathrm{t}$} & \multirow[b]{2}{*}{ Sig. } \\
\hline & & $\mathrm{B}$ & Std. Error & & & \\
\hline \multirow[t]{2}{*}{1} & (Constant) & 60.944 & 11.439 & & 5.328 & .000 \\
\hline & PREMI_PANEN & .854 & .194 & .591 & 4.398 & .000 \\
\hline
\end{tabular}

a. Dependent Variable: Kepuasan Kerja

Berdasarkan hasil uji regresi linier sederhana tersebut, maka dapat diketahui persamaannya sebagai berikut:

$$
Y_{2}=a+b X
$$

$Y_{2}=60.944+0,854 X_{2}+\mathrm{e}$

Keterangan:

$\mathrm{Y}_{2}=$ Variabel terikat (Kepuasan Karyawan)

$\mathrm{X}=$ Variabel Bebas (Premi Panen)

$\mathrm{a}=$ Konstanta (Nilai Y apabila $\mathrm{X}=0$ )

$\mathrm{b}=$ Koefisien Regresi (nilai peningkatan atau penurunan)

Berdasarkan persamaan tersebut maka dapat diketahui sebagai berikut:

Nilai konstanta (Y) sebesar 60,994 artinya jika variabel premi panen (X) nilainya 0 (nol), maka variabel kepuasan karyawan $\left(\mathrm{Y}_{2}\right)$ akan berada pada angka 60,994.

Koefisiens regresi X (Premi Panen) dari perhitungan linier sederhana didapat nilai koefisien (b) $=0,854$. Hal ini berarti setiap ada kenaikan premi panen $(\mathrm{X})$ maka kepuasan karyawan $\left(\mathrm{Y}_{2}\right)$ juga meningkat.

\section{Uji Reabilitas}

Tabel 7. Hasil Uji instrument penelitian (Uji Reabilitas) 
Fitra Aristia Fahmi Lubis, Siti Mardiana, \& Mitra Musika Lubis, Analisis Sistem Premi Panen Kelapa Sawit Terhadap Kinerja dan Kepuasan Kerja Karyawan

\begin{tabular}{lll}
\hline Reliability Statistics & & \\
\hline Cronbach's Alpha & Cronbach's Alpha Based on Standardized Items & N of Items \\
\hline .757 & .992 & 52 \\
\hline
\end{tabular}

Sumber: Data Primer diolah SPSS 22, 2019

Berdasarkan hasil uji reabilitas pada tabel 5. Dapat diketahui bahwa pernyataan pada kuesioner mempunyai Cronbach's alpha 0,757 lebih besar dari 0,6 artinya semuanya memiliki nilai reabiilitas yang tinggi, hal ini dapatdisimpulkan bahwa instrumen penelitian yang dipakai dapat dipercaya dan diandalkan.

\section{Uji Serempak (Uji F)}

Adapun tujuan dari uji simultan ini adalah untuk menguji hipotesis yang menjelaskan diduga terdapat pengaruh antara variabel premi panen $(\mathrm{X})$ terhadap kepuasan karyawan $\left(\mathrm{Y}_{2}\right)$. Untuk lebih jelas dapat dilihat pada hasil tabel 8berikut ini:

\begin{tabular}{|c|c|c|c|c|c|c|}
\hline \multicolumn{7}{|c|}{ ANOVA $^{\mathrm{b}}$} \\
\hline Model & & Sum of Squares & Df & Mean Square & $\mathrm{F}$ & Sig. \\
\hline \multirow[t]{3}{*}{1} & Regression & 269.044 & 1 & 269.044 & 19.345 & $.000^{\mathrm{a}}$ \\
\hline & Residual & 500.667 & 36 & 13.907 & & \\
\hline & Total & 769.711 & 37 & & & \\
\hline \multicolumn{7}{|c|}{ a. Predictors: (Constant), PREMI_PANEN } \\
\hline \multicolumn{7}{|c|}{ b. Dependent Variable: KEPUASAN_KERJA } \\
\hline
\end{tabular}

Berdasarkan dari hasil penelitian yang diperoleh, dapat dilihat pada tabel 22. Diatas diketahui bahwa F-hitung sebesar 19,345 sedangkan nilai F-tabel untuk pembilang (df1) adalah $\mathrm{K}-\mathrm{l}=2-1=1$, dan penyebut (df2) adalah $\mathrm{n}-\mathrm{k}=38-2=36$ dengan taraf signifikan sebesar 5\% adalah 4,11. Maka diketahui bahwa nilai f-hitung Variabel Premi Panen (X) yaitu 19,345 lebih besar dibandingkan nilai f-tabel yaitu 4,11 maka H0 ditolak H1 diterima. Begitu juga jika dilihat dari nilai signifikansi variabel premi panen (X) 0,000 < 0,05 maka H0 ditolak dan H1 diterima, jadi dapat dikatakan bahwa terdapat pengaruh antara variabel premi panen $(\mathrm{X})$ terhadap Kepuasan karyawan $\left(\mathrm{Y}_{2}\right)$.

\section{Variabel Premi Panen (X) Berpengaruh terhadap Kinerja Karyawan ( $\mathrm{Y}_{1}$ )}

Berdasarkan hasil penelitian diketahui bahwa premi panen $(\mathrm{X})$ berpengaruh signifikan terhadap kinerja karyawan $\left(\mathrm{Y}_{1}\right)$ hal ini berdasarkan pada nilai signifikansi variabel premi panen (X) sebesar 0,000 $<0,05$ atau nilai thitung $4.915>1,16$ nilai $t$ tabel. Sehingga dapat disimpulkan bahwa terdapat pengaruh yang signifikan antara variabel premi panen $(\mathrm{X})$ terhadap kinerja karyawan $\left(\mathrm{Y}_{1}\right)$.

\section{Variabel Premi Panen (X) Berpengaruh terhadap Kepuasan Karyawan ( $\left.\mathrm{Y}_{2}\right)$}

Berdasarkan hasil penelitian diketahui bahwa premi panen (X) berpengaruh signifikan terhadap kepuasan karyawan $\left(\mathrm{Y}_{2}\right)$ hal ini berdasarkan pada nilai signifikansi variabel premi panen (X) sebesar 0,000 0,05 atau nilai t-hitung 4,398 > 1,16 nilai t-tabel. Sehingga dapat disimpulkan 
bahwa terdapat pengaruh yang signifikan antara variabel premi panen $(\mathrm{X})$ terhadap kepuasan karyawan $\left(\mathrm{Y}_{2}\right)$.

\section{SIMPULAN}

Berdasarkan hasil penelitian, adapun kesimpulan yang dapat ditarik diantaranya sistem Premi Panen di PT. Perkebunan Nusantara III Kebun Rambutan adalah sistem basis tugas. Sistem Basis Tugas (BT) ditentukan berdasarkan kondisi topografi areal dan potensi produksi. Premi Panen berpengaruh nyata terhadap kinerja karyawan panen (kuantitas, kualitas, kehadiran) karyawan panen di PT. Perkebunan Nusantara III Kebun Rambutan. Premi berpengaruh nyata terhadap kepuasan kerja karyawan panen di PT. Perkebunan Nusantara III Kebun Rambutan.

\section{DAFTAR PUSTAKA}

A.A Anwar Prabu Mangkunegara. (2005). Manajemen Sumber daya Manusia Perusahaan. Bandung: PT Remaja Rosdakarya.

Rosdakarya.
. (2001). Manajemen Sumber Daya Perusahaan. Bandung: PT. Remaja
(2006). Perencanaan dan Pengembangan Manajemen Sumber Daya Manusia.Pen. PT. Refika Aditama.

Akbar P.S dan Usman. (2008). Pengantar Statistika. Jakarta: Bumi Aksara

Amstrong, M. (1999). Manajemen Sumber Daya Manusia. Terjemahan Sofyan dan Haryanto. Jakarta: PT. Elex Media Komputindo.

Amizi. (2016). Job Satisfaction Among Malaysian Youth Working in The Oil Palu Plantation Sector. Skripsi. Universiti Utara Malaysia.

Ashar, M. (2008). Psikologi Industri dan Organisasi. Jakarta: Universitas Indonesia.

As' ad, M. (1995). Psikologi Industri. Yogyakarta: Liberty

Brotoharsojo, H \& W. (2003). Tingkatkan Kinerja Perusahaan dengan Merit System. Jakarta: PT. Rajagrafindo Persada.

Davis, Keith dan John W. Newstrom. (1985). Perilaku Dalam Organisasi. Jakarta: Erlangga

Fachreza. (2014). Hubungan Sistem Premi Kelapa Sawit dengan Kinerja dan Kepuasan Kerja Karyawan PT. PP. London Sumatera Utara. Medan: Universitas Sumatera Utara.

Fauzi, Y. (2004). Seri Agribisnis Kelapa Sawit Budidaya Pemanfaatan Hasil Dan Limbah Analisis Usaha Dan Pemasaran. Edisi Revisi. Jakarta: Penebar Swadaya.

Ghani, M. A. (2003). Sumber Daya Manusia Perkebunan Dalam Persepektif. Jakarta: Ghalia Indonesia.

Gibson. (2010). Organisasi Perilaku Struktur Proses. Edisi ke-5 Jakarta: Erlangga.

Ghozali, I. (2006). Aplikasi Analisis Multivariate dengan Program SPSS (Edisi ke-4. Semarang: Badan Penerbit Universitas Diponegoro

Greenberg, J. dan Baron, R.A. (2003). Behavior in Organizations Understanding and Managing. The Human Side of Work. Nwe Jersey: Prentice - Hall International

Greenberg, J. \& Baron, R.A. (2007). Behavior in Organization. Prentice Hall (9th Edition) As'ad, 1995. Psikologi Industri. Yogyakarta: Liberty.

Handoko, T. Hani. (2001). Manajemen Personalia dan Sumber Daya Manusia. Yogyakarta: BPFE Yogyakarta. Hasibuan. (2002). Manajemen Sumber Daya Manusia. Jakarta: Bumi Aksara.

Howell, William C \& Robert L. Dipboye. (1986). Essential of Industrial and Organizational Psychology, 3rd ed. Chicago Illinois: Dorsey Press.

Husein. (2008). Metode Penelitian Untuk Skripsi dan Tesis Bisnis. Jakarta: PT Rajagrafindo Persada.

Kasiram, Moh. (2008). Metodologi Penelitian. Malang: UIN-Malang Pers.

Kreitner R, \& Kinicki, A. (2001). Organizational Behavior, Fith Edition, International Edition, Mc Graw-Hill companies. Inc

Lily. S. S. (2013). Faktor-Faktor Yang Mempengaruhi Produktivitas Tenaga Kerja Karyawan Pemanen dan Pemupuk di PTP. Nusantara IV. Medan: Universitas Sumatera Utara.

Luthans, F. (2006). Perilaku Organisasi. Edisi Sepuluh. Yogyakarta: PT. Andi.

Martoyo. (1994). Manajemen Sumber Daya Manusia. Yogyakarta: BPFE

Mathis, R.L, Jackson, J.H. (2006). Manajemen Sumber Daya Manusia. Jakarta: Salemba Empat.

Moeheriono. (2010). Pengukuran Kinerja Berbasis Kompetensi. Surabaya: Ghalia Indonesia. 
Fitra Aristia Fahmi Lubis, Siti Mardiana, \& Mitra Musika Lubis, Analisis Sistem Premi Panen Kelapa Sawit Terhadap Kinerja dan Kepuasan Kerja Karyawan

Nawawi. (2005). Penelitian Terapan.Yogyakarta: Gajah Mada University Press.

Nasution R.A. (2016). Pengaruh Premi Panen Terhadap Kinerja Karyawan Panen Unit Kebun Pada PT. Perkebunan Nusantara III (Persero) Medan Kebun Rambutan. Skripsi. Universitas Sumatera Utara.

Pahan, I. (2007). Panduan Lengkap Kelapa Sawit Manajemen Agribisnis Dari Hulu hinggga Hilir. Cetakan kedua. Jakarta: Penebar Swadya.

Pratama, F. (2013). Perancangan Aplikasi Informasi Budidaya Kelinci Berbasis Android. Skripsi. Jurusan Teknik Informatika. Yogyakarta: Sekolah.

Purnama. (2010). Pengaruh Premi Panen Terhadap Kinerja dan Kepuasan Kerja Karyawan Panen Kelapa Sawit. Skripsi. Universitas Sumatera Utara

Robbins, S dan Coulter, Mary. (2002). Manajemen. Jakarta: Gramedia.

Robbins, Stephen P. (2003). Organizational Behavior. Pearson education. New Jersey 07458. 37-39.

Sandriani. (2014). Faktor-Faktor Yang Mempengaruhi Kepuasan Kerja Karyawan Bagian Perkebunan Pada PT. Perkebunan Nusantara V Kebun Air Molek I Kabupaten Indragiri Hulu. Skripsi. Universitas Islam Riau.

Sarasvathy. (2013). Identifying Factors That Influence Job Perfomance Amongst Employess in Oil Palm Plantation - FASS Final Project (Psychology). Faculty of Applied Social Sciences, Open University Malaysia.

Sedarmayanti. (2001). Manajemen Sumber Daya Manusia dan Produktivitas Kerja. Bandung: Mandar Maju.

Simamora, B. (2003). Memenangkan Pasar dengan Pemasaran Efektif \& Profitabel. Jakarta: Gramedia Pustaka Utama.

Situmorang. (2012). Analisis Data Untuk Riset Manajemen dan Bisnis. Edisi-2. Medan: USU Press.

Sopiah. (2008). Perilaku Organisasi. Yogyakarta: Andi Offset.

Sugiyono. (2017). Metode Penelitian Kuantitatif, Kualitatif, dan R\&D. Bandung: CV. Alfabeta

Wibowo. (2007). Manajemen Kinerja. Jakarta: PT. Raja Grafindo Parsada.

Wirawan. (2009). Evaluasi Kinerja Sumber Daya Manusia Teori Aplikasi dan Penelitian. Jakarta: Salemba Empat. 